Published version Journal of Manufacturing Technology Management

\title{
An exploratory survey of current practice in the medical device industry
}

Julie Eatock, Dorian Dixon and Terry Young

Julie Eatock, DISC, Brunel University, Uxbridge, Middlesex, UB8 3PH, UK

Email: $\underline{\text { Julie.Eatock@brunel.ac.uk }}$

Dorian Dixon, NIBEC, University of Ulster, Jordanstown Campus, Shore Road Newtownabbey, Co. Antrim, BT37 0QB, UK

Email: d.dixon@ulster.ac.uk

Terry Young, DISC, Brunel University, Uxbridge, Middlesex, UB8 3PH, UK

Email: Terry.Young@brunel.ac.uk

Word Count (excluding references) 4809

General Review Paper 


\section{An exploratory survey of current practice in the medical device industry}

Purpose: This study was undertaken to examine the extent to which mainstream tools and strategies are applied in the medical devices sector, which is highly fragmented and contains a high percentage of small companies, and to determine if company size impacts on manufacturing strategy selection.

Methodology: A questionnaire was developed and disseminated through a number of channels. Responses were received from 38 companies in the UK and Ireland, describing 68 products taken to market in the past five years.

Findings: Because of the limited scope of the survey, the findings are indicative rather than conclusive, and interesting trends have emerged. New to the world products were much more likely to exceed company expectations of market success compared to derivative products. It was found that the majority of these innovative products were developed by small companies. Large companies appear to favour minor upgrades over major upgrades even though these prove - on the data presented - to be less successful overall.

Value of paper: These results provide those engaged in this sector with comparative information and some insights for further improvement. The reported trends with respect to company size and product complexity (or degree of novelty) are particularly illuminating. Academically, this sets some expected trends on a firmer footing and unearths one or two unexpected findings.

Originality: We believe this is the largest survey of determinants of success in UK medical device companies and to provide a comparison with other sectors.

Keywords: Medical Devices; Survey; Manufacturing Strategies; Project Complexity; Company Size.

\section{Introduction}

The Medical Devices Directive 93/42/EEC (1993) defines a device as:

"any instrument, apparatus, appliance, material or other article, whether used alone or in combination, including the software necessary for its proper application intended by the manufacturer to be used by human beings for the purpose of:

diagnosis, prevention, monitoring, treatment or alleviation of disease,

diagnosis, monitoring, treatment, alleviation of or compensation for an injury or handicap,

investigation, replacement or modification of the anatomy or of a physiological process,

control of conception,

and which does not achieve its principal intended action in or on the human body by pharmacological, immunological or metabolic means, but which may be assisted in its function by such means."

Embedded in this definition are many of the features that make the medical device sector an unusual one. The compass of the definition, for instance, is reflected in a very broad range of products, ranging from simple items such as an adhesive plaster through to implantable cardiac stents. These, in turn, are brought to market by a supply base consisting of many very small companies, a number of which are university spin-outs, in addition to large international players. The Health Industries Task Force Report (2004) estimates that there are 4,800 companies active in the UK, $85 \%$ of which turn over less than $£ 5 \mathrm{M}$ per annum. Globally, this market was estimated at around \$169 Billion in 2000 (AdvaMed, 2000). The wider delivery of healthcare around the world is increasingly reliant upon technological support and according to OECD figures (2006) consumed \$3.6Trillion in 2004 and is rising.

The fragmentation alluded to above, with its preponderance of small manufacturers and wide range of purchasing organisations, is one feature that sets the medical device sector apart from others. In particular, compared to sectors such as pharmaceuticals, such a landscape is 
much less likely to produce widely accepted standard processes, due to the prevalence of small and very small companies from a range of backgrounds.

Ironically, however, this is one of the more highly regulated sectors. Under the medical device directive (1993) medical devices will at least require CE marking to assure safety and performance if they are to be sold in Europe (or FDA approval for American markets), and manufacturers increasingly will be required to furnish evidence of effectiveness, and most recently of cost effectiveness (National Institute for Clinical Excellence, 2004) to achieve sales.

The wide definition also reflects a wide customer base, which is spread across public and private organisations and includes personal purchases. Finally, the fact that many medical devices are bought on behalf of the end user - either by a government or private agency undermines the customer-supplier relationship. The loss of this relationship makes it more difficult for consumer forces to shape the products on offer to both patients and other users.

Given these factors, it is not surprising that this is a difficult sector in which to operate; that many ideas are never brought to market; and that others fail to provide the expected returns. As already stated there are many start-up companies working within the industry, relying on a single device or a single piece of technology, and as the cost of failure is high it is difficult for these companies to survive a failure in the marketplace.

A range of tools and strategies have been proposed to make new product development more efficient and increase the success of new products in the market. However, very little evidence exists regarding the utility of these approaches in the medical device sector. Even in the 'grey' literature where articles can be found about turning ideas into products very little relates to the manufacturing aspects of this process (see for example Dunkerton, 2007; Erlandson, 2007). Given the paucity of data concerning current practice, this paper presents a survey which aims to provide an indication of which manufacturing strategies are used by companies, and to investigate if company size has an impact on product and strategy selection, and whether there was any relation between innovation and success.

\section{Strategies for design and manufacture}

Manufacturing has developed rapidly in the last century, from early mass production to mass customisation in the closing years. According to Copley (1923) the foundational steps for improved manufacturing strategies were laid by Frederick W. Taylor, which was later followed up by such people as Juran (1979), Schewart (1986), Ohno (1988), and Deming (2000).

These methods began to make an impact in western industry from the ' 70 s onwards, and they continued to evolve. Today, there is a wide range of such philosophies, including the Theory of Constraints (Goldratt and Cox, 1993; Goldratt, 1994), Just in Time (Harrison, 1995), Six Sigma (Harry and Schroeder, 1999), Lean Thinking (Womack and Jones, 2003) and Total Quality Management (Hill and Wilkinson, 1995). These methods tend to focus on quality and efficiency rather than cost reduction as their primary method of improving manufacturing. Smith and Reinertsen (1998) suggest that tradeoffs exist between performance dimensions, requiring that objectives be balanced, while Swink et al. (2006) argue that an inverse relationship exists between the naivety with which techniques are applied in new product development projects and the potential gain.

The connections between higher quality, lower manufacturing costs and greater customer satisfaction, were thus established, embedding the belief that "...implementation of quality management, continuous improvement training, and investment in technology ... would lead to superior performance" (Flynn 1999, quoted in Laugen et al., 2005), though this has only been confirmed in a few studies (Laugen et al., 2005). With respect to TQM, for instance, Hill and Wilkinson (1995) note dryly, 'the original "gurus" of quality management have been long on prescription but shorter on analysis, and moreover, have differed among themselves.' While many of these methodologies are both firmly embedded in other sectors and continue to be developed, many questions remain about the applicability of such techniques to medical devices, and the extent to which they are making an impact in this sector (Zirger and Hartley, 1996).

This paper makes several contributions to the study and practice of medical device development. Although data has been difficult to gather, and is still quite sparse, it represents 
the largest survey of this type in the UK and Ireland in the sector that we are aware of. Given the size and impact of this sector, this is in itself important.

\section{Research Method}

The method used was to base the initial questions on a literature search around new product development and the findings of other research being conducted with a cohort of industrial partners engaged with the MATCH programme. This background included an extended interview conducted with new partners and visits made to a number of industrial sites. A questionnaire was designed and distributed in 2006, and analysed the responses from 38 companies, providing information on 68 medical products launched within the UK and Ireland within the last 5 years. The central research question was: which manufacturing strategies are used by medical device manufacturers, and does company size impact on the strategy selection or level of innovation.

The literature survey and the team's experience combined with a pair of in-depth interviews indicated a number of approaches in terms of industrial methods, project management and team management that were likely to be prevalent within the sector. These were:-

-QFD. Quality Function Deployment “...was developed to bring a personal interface to manufacturing and business." (QFD Institute, accessed 2006) It is concerned with capturing the customer's (end user's) spoken and unspoken needs and translating these into the product design and monitoring these specifications through development.

-DFM. Design for Manufacture "is the practice of designing products with manufacturing in mind. Its goal is to reduce costs required to manufacture a product and improve the ease with which that product can be made" (Driscoll, 2002).

- Stage gates - Championed by Cooper et al. (2002a; 2002b) this NPD method consists of a 'stage' where a series of tasks are completed and a 'gate' where the project is tested against certain criteria and proceeds to the next 'stage' if it passes, and is filed away if it fails.

- Concurrent Engineering. This strategy aims to shorten the overall design time by better defining the product and better documentation of the design process. In order to achieve this, appropriate disciplines are committed to work in parallel to conceive, approve, develop, and implement every aspect of a product's development process (Zayas-Castro et al., accessed 2006; Wen, 1998).

- Lean "... provides a way to do more and more with less and less... while coming closer and closer to providing customers with exactly what they want" (Womack and Jones, 2003). It does this by adopting a customer-derived view of value and an intensely product-centred view of development processes in order to reduce waste and streamline the manufacturing process.

- Six Sigma. In many organisations this "simply means a measure of quality that strives for near perfection. Six Sigma is a disciplined, data-driven approach and methodology for eliminating defects (driving towards six standard deviations between the mean and the nearest specification limit) in any process - from manufacturing to transactional and from product to service" (iSixSigma, accessed 2006)

-TQM. "ISO 8402:1994 defines total quality management (TQM) as a management approach of an organisation centred on quality, based on the participation of all its members and aiming at long-term success. This is achieved through customer satisfaction and benefits to all members of the organisation and to society. In other words, TQM is a philosophy for managing an organisation in a way which enables it to meet stakeholder needs and expectations efficiently and effectively, without compromising ethical values." (Institute of Quality Assurance, accessed 2006).

-FMEA (failure modes and effects analysis) - "is a team-based, systematic and proactive approach for identifying the ways that a process or design can fail, why it might fail, and how it can be made safer" (Latino, 2004). It involves analysing "potential reliability problems early in the development cycle where it is easier to take actions to overcome these issues, thereby enhancing reliability through design" (Crow, 2002) 
-DOE - Design of Experiments "is one of the powerful tools used to investigate deeply hidden causes of process variation. DOE techniques are useful for surfacing the effects of hidden variables, and studying possible effects of variables during process design and development. Experiments range from uncontrollable factors introduced randomly to carefully controlled factors". (Konda et al., 1999; Dixon et al., 2006b)

-End User. This relates to the level of end-user involvement in the design and development processes. This has long been attributed to the successful use of products but has traditionally a very low uptake (Gould and Lewis, 1985)

- Parts Supplier. "Suppliers are included in the development process because they frequently possess design and technology expertise." (Birou and Fawcett, 1994).

- Cross Functional Team. This refers to a team composed with members from different functional experiences and abilities working together towards a common goal (Wen, 1998).

- Dedicated Team. This refers to the case where a team of core workers is assembled for a substantial part of the product development cycle, which has no significant responsibilities outside the produce development process itself, improving understanding of, and commitment to, the project (Kandemir et al., 2006).

A pilot version of the survey was produced and trialled for clarity and utility with a small group of interested parties. Note that the terms above were used but definitions were not offered to those filling in the questionnaire.

Part I of the questionnaire included questions concerning the company itself to determine the size of the company, how long it had been established and how many units it produced each year, whether items were produced to order or to stock, and the number of new products produced in the last five years.

Part II and Part III of the questionnaire asked about a 'more successful' and a 'less successful' product produced in the previous five years. The questions in both sections are identical. Some of the questions included in the questionnaire are beyond the scope of this paper, but are addressed elsewhere (e.g. Dixon et al., 2006a). The full question set is included as an appendix.

For each product, respondents were asked to grade the perceived success of the product on a five point scale of "much more successful", "slightly more successful", "as successful", "slightly less successful" or "much less successful" than anticipated. As the medical device industry is so diverse, metrics such as return on investment or units sold as a measure of success are inappropriate in this instance. Relative success i.e. actual success against anticipated success as assessed by the company, was therefore used as an alternative measure. They were then asked to rate the complexity/technical challenge presented by the project as a "minor product development/upgrade", "a major development/upgrade using existing technology", "a new product using existing technology", or a "new product using new technology". Respondents were asked to classify the product in terms of the company's current market as either "existing market", extension to existing market", "new market to the company" or a "new market to the world". The manufacturing strategies described above were listed and respondents were asked if they used the strategies and to what extent during the development of the particular product.

The questionnaire was distributed initially, as a pre-paid insert in a trade magazine. To stimulate interest, an article was written to explain the study and a further article containing early dissemination of results was promised (Dixon et al., 2006a). The study then moved into a phase of securing responses through a much wider variety of channels, including events, exhibitions, the ABHI (Association of British Healthcare Industries), MATCH partners, and the MATCH website. This ultimately resulted in a response of 68 products from 38 companies (not every respondent gave both a successful and an unsuccessful product). Table 1 gives a breakdown of the source of the response set. 


\begin{tabular}{lcc}
\hline & Number of responses & Percent \\
\hline MDT magazine & 9 & 23.7 \\
MedTec & 2 & 5.3 \\
ABHI + MATCH partners & 7 & 18.4 \\
MATCH events & 10 & 26.3 \\
Medica exhibit list & 1 & 2.6 \\
On-line & 9 & 23.7 \\
Total & 38 & 100.0 \\
\hline
\end{tabular}

Table 1. Sources of responses

In order to validate the findings of the questionnaire data from an earlier series of in-depth interviews with medical device manufacturers was examined for companies that had responded to both the interviews and the survey. These interviews took place as part of the $\mathrm{MATCH}$ research project during the summer of 2004 - within the period covered by the questionnaire. Each of the company representatives was asked a set of questions in an open dialogue which was recorded and then transcribed. The interview began by asking the representative about aspects of the business such as turnover and headcount, and then they were asked to select a particular product which they used as a basis for answering the rest of the questions. The interviewee was then asked a series of questions concerning all aspects of the product including, amongst other things, its purpose, its users, its development process, regulatory and reimbursement issues. The interviewee and the respondent to the survey were not necessarily the same person, and the products that were selected would also not necessarily be the same product, but it was felt that this would provide a backdrop with which to compare the survey findings. For the purposes of this paper two of the companies that provided interviews have been selected, one a micro company the other a large company, and their responses have been compared to the questionnaire findings.

The strength of this instrument was its coverage of a very wide range of factors in new product development within the health technology sector. Also, there are few such surveys in existence, and none, to our knowledge, in the past five years. However the low response rate and the limited sample size restrict the statistical analysis that can be performed, which in turn limits the way in which the results might be generalised. However, the sample size of 68 new medical device products represents a significant examination of the sector.

\section{Results}

From the 38 companies that responded, providing information on 68 separate products, question 2 showed that if we use the European Commission (2003) definition of company size then we could classify the respondents into the following groups

- $23.7 \%(n=9)$ were from micro companies (fewer than 10 employees),

- $10.5 \%(n=4)$ were from small companies (between 10 and 49 employees),

- $28.9 \%(n=11)$ were from medium-sized companies (between 50 and 250 employees)

- $36.8 \%(n=14)$ were from large companies (more than 250 employees).

The products were categorised by the size of the company and whether the product was a minor upgrade, a major upgrade, a new product that used existing technology or a new-tothe-world product (Questions 11 and 25). The results are shown in Table 2 and graphically in Figure 1.

\begin{tabular}{|c|c|c|c|c|c|c|}
\hline & & $\begin{array}{c}\text { minor } \\
\text { upgrade }\end{array}$ & $\begin{array}{c}\text { major } \\
\text { upgrade }\end{array}$ & $\begin{array}{c}\text { new product } \\
\text { existing tech }\end{array}$ & $\begin{array}{c}\text { new product } \\
\text { new tech }\end{array}$ & Total \\
\hline \multirow{3}{*}{$\begin{array}{c}\text { Size of } \\
\text { organisation }\end{array}$} & micro & $18.75 \%(n=3)$ & $37.5 \%(n=6)$ & $25 \%(n=4)$ & $18.75 \%(n=3)$ & 16 \\
\cline { 2 - 8 } & small & $12.5 \%(n=1)$ & $12.5 \%(n=1)$ & $50 \%(n=4)$ & $25 \%(n=2)$ & 8 \\
\cline { 2 - 8 } & medium & $15 \%(n=3)$ & $30.0 \%(n=6)$ & $45 \%(n=9)$ & $10 \%(n=2)$ & 20 \\
\cline { 2 - 8 } & large & $33.33 \%(n=8)$ & $4.17 \%(n=1)$ & $50 \%(n=12)$ & $12.5 \%(n=3)$ & 24 \\
\hline \multicolumn{2}{r|}{} & 15 & 14 & 29 & 10 & 68 \\
\hline
\end{tabular}

Table 2. Product type by size of organisation 


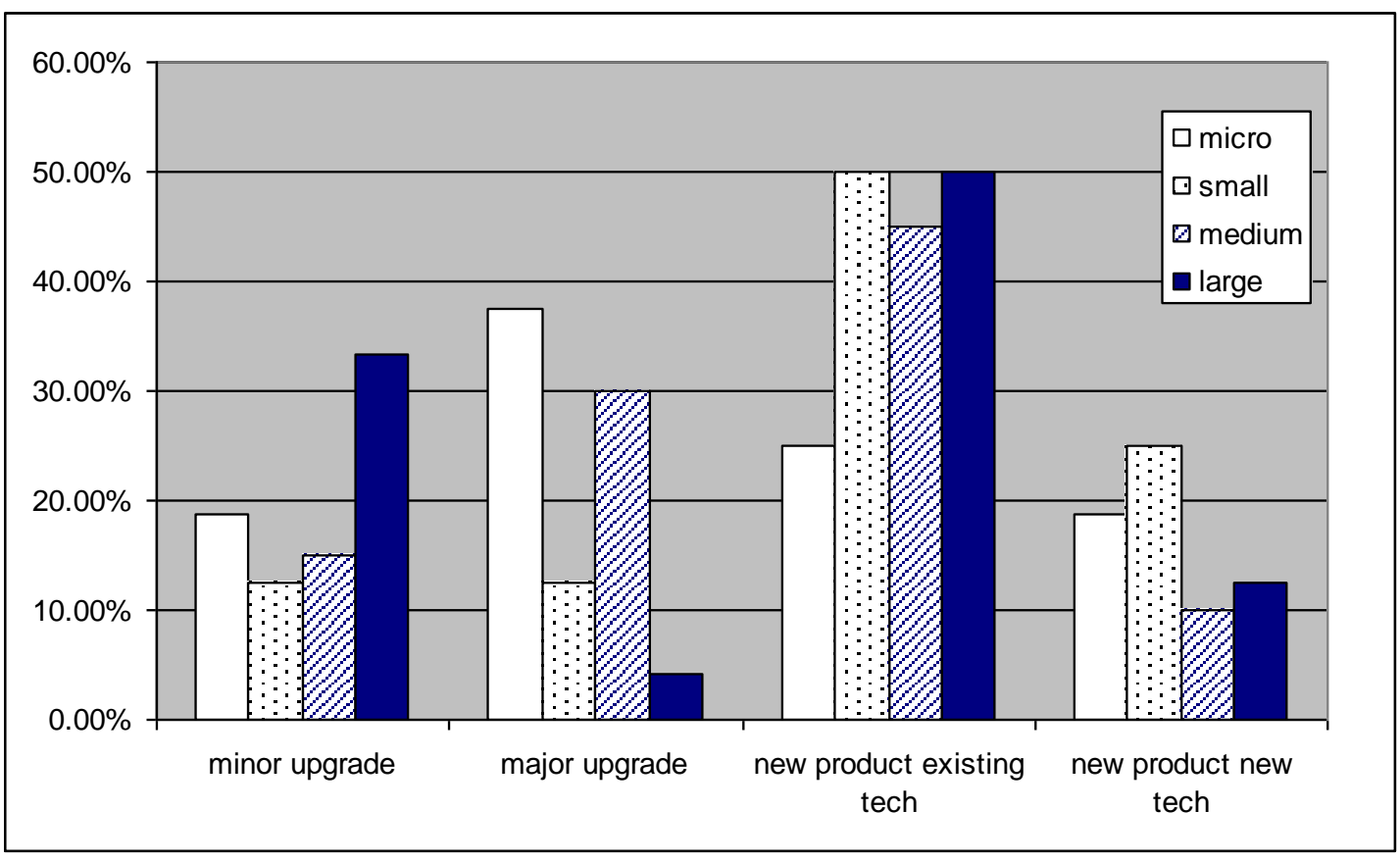

Figure 1 Products surveyed by company size and type

From the graph it can be seen that all the companies with the exception of the micro companies seem to launch a high proportion of new products using existing technologies, micros companies appear to prefer major upgrades. The possible reasons behind this may be that micro-sized companies may only have a very limited product range and therefore have to ensure that they channel their resources into making their products more innovative to compete with the larger companies. They may hope to be bought up by big companies or possibly float their company on the stock market.

The products were categorised by the market that the product was aimed at (questions 12 and 26 ); $7.6 \%$ were aimed at new-to-the-world markets, $42.4 \%$ were aimed at existing markets, $37.9 \%$ were aimed at extending the current markets, $12.1 \%$ were aimed at new markets for the company.

The complexity of the product was then examined against its perceived success (questions 9 , 11, 23, and 25). The results are shown in Figure 2.

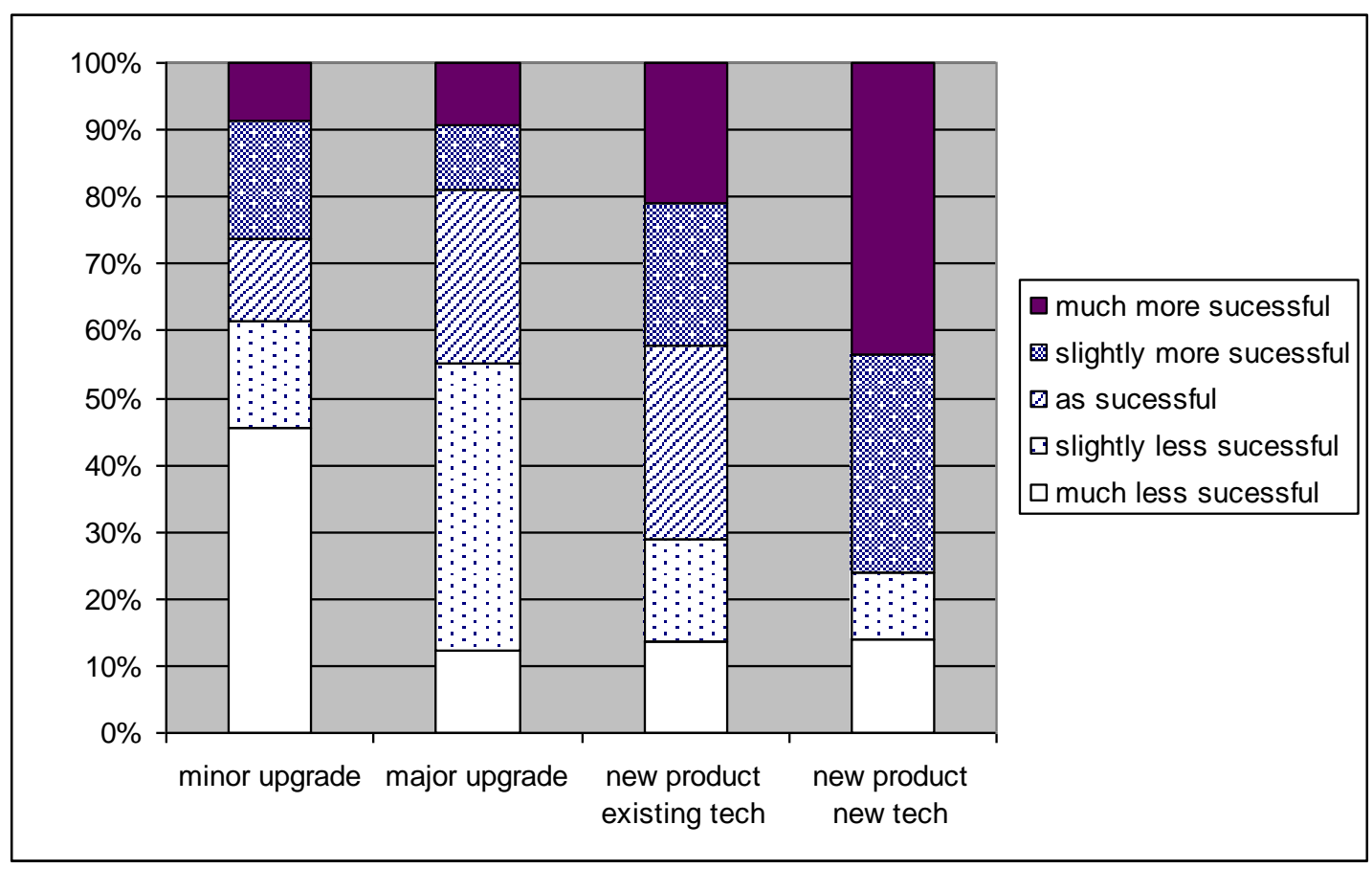

Figure 2 Complexity of product and perceived success 
This provided some very interesting results. For instance, minor upgrades were the least successful of the four levels of complexity with as many as $66 \%$ failing to live up to expectations. This fact makes it particularly surprising that the large organisations, which presumably, have more options available are the most likely to invest in minor upgrades rather than major upgrades (Figure 1). At the other end of the scale more than $70 \%$ of the new products that used new technologies proved to be more successful than anticipated. Comparing the manufacturing strategies with company size (questions 2, 15 and 29) provided the information depicted in Figure 3.

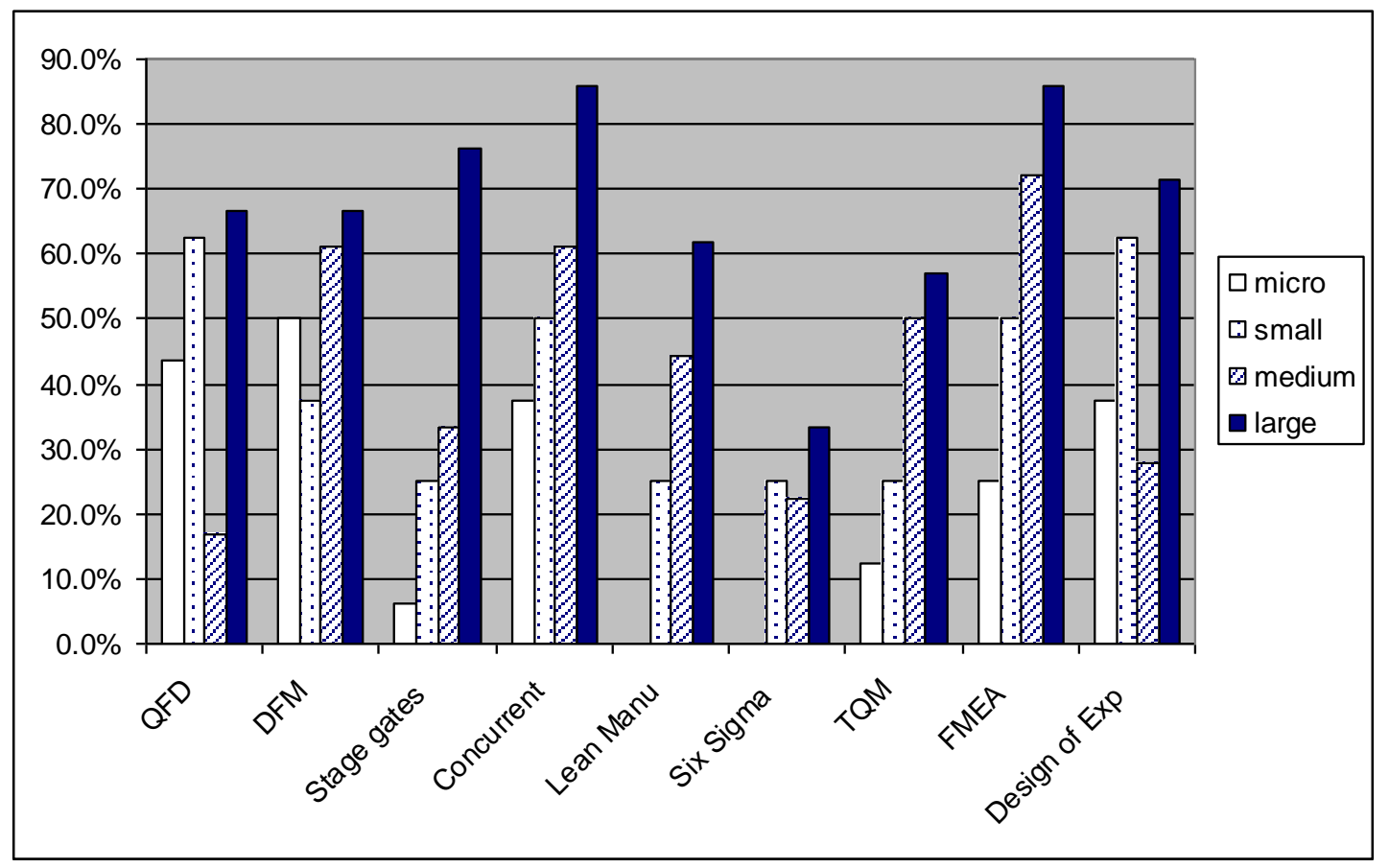

Figure 3 Size $v$ manufacturing strategies

Stage gates, lean, six sigma and TQM have very low take-up if any, in the micro companies, but strategies such as QFD and DFM have a much larger take-up in these companies. We wonder if this is because small and micro companies may be the product of university spinouts and, as Cha and Xin (2006) demonstrated, these methods were more popular with academics than their manufacturing counterparts. Another factor may be that unlike company wide quality philosophies such as TQM and Six-Sigma, QFD and DFM are both concise NPD tools and may therefore be more applicable in small companies. There is, of course, always the possibility that companies claiming to implement a given method may not be doing so particularly rigorously. In describing the way in which TQM was adopted in British Industry, Hill and Wilkinson (1995) note "Companies seem to pick up bits and pieces of TQM and then report that they are operating TQM, when in reality most schemes appear an ill-matched mixture of quality circles, employee involvement, quality tools and long-established quality assurance systems". Another interesting finding is that most large companies have experience with all the major methods, and moreover, appear to using several in parallel.

Generally the take up of a particular strategy increases with the size of the company. The main exceptions to this trend are QFD and Design of Experiments which appear to have little take-up in the medium-sized companies.

The difference when compared with previous research statistics is, in some cases quite surprising. For instance, in his paper Booker (2003) cites Araujo and Benedetto-Neto (1996) in stating that the uptake of DFM is $90 \%$ across industries in the UK, whereas this survey showed the average uptake across the medical device industry as much lower at $56 \%$. When FMEA uptake is compared with the same study the findings are similar for the large and medium sized companies but lower for the small and micro companies in the medical device industry. QFD, on the other hand appears to have a higher uptake within the medical device industry then as a whole ( $46 \%$ compared with $30 \%)$, as does DOE (50\% compared with 
$30 \%)$. The other strategies in this survey were not reported on in the previous research, so it is difficult to make a comparison in uptake.

In order to validate the findings of the questionnaire two companies were chosen and their representatives interviewed in more depth about their product development. Company $A$ is a micro company employing fewer than 10 people with a turnover in the region of $£ 1 / 2 m$, while Company B is a global company that employs more than 2000 people in the UK alone, and with a UK turnover in the region of $£ 600 \mathrm{~m}$. Both companies were asked identical questions during their interviews.

When asked about the manufacturing strategies that they used during product development and manufacturing the representative of Company A claimed they used FMEA, numerical modelling, fluid dynamics, and stated that the customer was very heavily involved with the design process. However he also noted that they definitely did not use JIT, stage gates or sixsigma. The representative of Company B, on the other hand, stated that they attempted to use lean manufacturing techniques but admitted they were not a 'shining example' of this. They also used stage gates and concurrent engineering techniques and believed they did these ones effectively. However, they specifically stated that they did not use six-sigma, TQM or DOE in their product development and manufacturing processes.

In terms of our survey findings these comments validate our findings in that the smaller companies are more likely to use more analytical techniques in their product development than process management techniques, whereas the larger company mentioned process management techniques - though this does not imply that they do not use analytical techniques also. The interviews also validate the finding that six-sigma does not appear to be heavily used in medical device manufacturing companies.

The companies were asked to talk about the products that they develop, their advantages or disadvantages over their competitors and their successes and failures within the market.

Company A likes niche markets with cutting edge technology and produce new-to-the-world type products. They anticipate success as they work closely with surgeons who are waiting for delivery of the device. Assuming that the device is successful they expect the company to be bought up by a larger company within that particular field. Their biggest disadvantage is their size in comparison to their competitors, and although their product is new-to-the-world this is not a major disadvantage. Funding for the company has at least partially come through venture capital. Their biggest hurdle is seen as the regulatory issues surrounding the device.

Company $B$ has a wide range of products covering all classes and a number of medical specialities. It sees its biggest advantage as being brand - which is well respected in all the specialties - as well as access to cash. Many of the products that they are currently working on are second or third generation of products that are already successful in the market. As well as having many successful products they were willing to discuss a few products that had failed in the market, some of which needed complete redesign, and others which simply failed to sell the anticipated numbers.

One implication from these interviews is that Company $B$ was able to withstand these failures due to available cash-flow, whereas it is not clear that Company $A$ could withstand a failure in its product.

Again the interviews validated the questionnaire in that micro companies preferred new-tothe-world type products, whereas larger companies prefer to utilise existing technologies

\section{Discussion}

Due to the difficulty in obtaining information on recently launched medical devices the somewhat limited sample size limits the statistical analysis. However, combined with the indepth interviews we believe that the findings give an indication of current practice in the medical device industry and therefore even without the desired statistical rigour provide interesting results.

The study has not taken account of how long or how well any of the techniques may have been used in this particular setting, other than was implied by the request to select projects 
from the past five years. There is therefore no evidence of how experienced managers are at utilising the techniques, how fully they are implemented, or how rigorously they are applying them, and therefore whether they are getting the best out of them (Swink et al., 2006). The survey investigates use of tools and techniques across the sector rather than the rigour of their application. This said, it does not mean that the findings of the survey are not valid, or that they do not provide interesting avenues for further research and development.

Some of the results from the survey supported expected findings such as indicating that the uptake of formal manufacturing strategies - such as Lean, Six Sigma and even TQM and Stage Gates - amongst micro companies is very limited, and only about a quarter of small companies use them (Achanga et al., 2006; Thomas and Barton, 2006). However the use of QFD and DFM in the micro companies is much higher than would otherwise be expected.

With the exception of Six Sigma, which overall has a much smaller uptake with device manufacturers, the picture is quite different for large companies. Almost $60 \%$ identify themselves as using TQM - a figure that rises above $70 \%$ for stage gates, and above $80 \%$ for concurrent engineering. Among the large companies the uptake of all the techniques except for stage gates is above $50 \%$, indicating that many large companies are using several of these techniques at once, perhaps in parallel.

The data also provides evidence that large companies tend to adopt incremental strategies and avoid developing new products using new technologies, and yet the former is a disappointment most of the time, while the latter exceeds expectations most of the time. While the case is not conclusively compelling, there is a suggestion here that larger companies have something to gain by taking slightly greater risks.

Another not unexpected result supported by the data suggests the favoured option by almost $50 \%$ of all companies (excepting micro companies) is to develop the new product using existing technology. In terms of outcome, this strategy represents a high probability of satisfaction $(>35 \%)$, with the chance of pleasant surprise very slightly better than risk of disappointment. However, the data suggests that the most rewarding option on these figures is to develop a new product on new technology. Again, the contrast between small companies and large companies is marked here. Almost twice as many products from small companies fall into this category than products from large companies - and nearly $70 \%$ of those taking this route are pleasantly surprised by the outcome. One possibility for the higher than expected success rate of the small and micro companies with new-to-the-world technology products is that this may be due to the elimination of the instances when the product has been unsuccessful (and consequently the company has gone out of business). Thus the only firms in a position to participate in the study may have been ones with successful products.

The data also produced some notable results such as the finding that more than $30 \%$ of large company product launches are in the form of a minor upgrade as opposed to a major upgrade (an option chosen only $5 \%$ of the time), and yet this strategy appears to result in disappointment more than $60 \%$ of the time. This raises the question as to why, if this evidence is truly reflective of the wider community, the companies which presumably have the greatest opportunity to choose their strategy, select one which is so disappointing. The newto-the-world type projects are done by the micro and small firms and tend to be more successful, which could imply that the innovation strategy adopted by larger organisations is to buy up the small companies once the products have proved to be successful, reducing their risk of failure, and accounting for the tendency to produce minor upgrades.

The data also provided us with a number of avenues for further exploration. For instance, the questionnaire does not provide the answers as to why $70 \%$ of new-to-the-world projects are more successful than anticipated. Does more research go into the starting stages of the product development cycle in developing a new-to-the-world product? Is there a greater effort put into eliciting user needs and designing for those needs? Does more effort go into marketing the product? Undoubtedly all these factors affect the success of the product but more research is needed into whether they have a greater impact on new-to-the-world products than on those that are new to the organisation. Furthermore the data does not provide answers to the question of whether a greater percentage of these products are produced by science park or university spin out companies which may have a different business strategy to other larger or more established companies. This may be an avenue for further exploration. 
The data also suggests that $66 \%$ of products defined as minor upgrades were less successful than anticipated when launched. However the majority of products launched by large companies fall into this category. Do they have a need to keep the existing customers happy by acting on feedback received, even though they know that this may not produce the sales expected? On examining the data more closely to determine whether it hid the possibility that the larger companies' minor upgrades were in fact generally more successful than smaller companies' minor upgrades, it revealed that of the large companies' minor upgrades as many as $50 \%$ were considered 'much less successful' and a further $12.5 \%$ were considered 'slightly less successful'. A larger data set would enable a higher degree of confidence in the results regarding particular subgroups. Further research could be undertaken to see if this is a trend, and if this proves to be so, examine why this may be.

Finally, other possible avenues for future research include determining why strategies such as stage gates, lean, six sigma and TQM have such low uptake especially in the smaller sized companies, and is there such a thing as 'strategy fatigue' where the effects of introducing a strategy originally wear off after a time?

\section{Conclusions}

From the results of this questionnaire we can determine that data is very difficult to obtain and perhaps for this reason there appears to be very little literature giving a detailed breakdown of successful and unsuccessful products in the medical device industry.

The research has, however, provided us with a picture of the industry and has allowed identification of some interesting areas for future research. The results can be classified into four categories; expected and supported, not unexpected and supported, surprising findings, and areas for further research. The key findings from the survey are listed below.

- Expected and supported

- large companies use a wider range of methods,

- small companies have a very low uptake of lean, six sigma, stage gates and TQM

- Not unexpected and supported

- large companies like to stick with known technologies

- the survey findings proved consistent with innovation model where large companies buy up the new technology they need

- large companies use a number of different methods possibly in parallel

-small companies prefer new-to-the-world technologies

- Surprising findings

- major upgrades versus minor upgrades are favoured by the large companies even though the success rate of major upgrades is lower than that of minor upgrades

- high success rate reported by those with new-to-the-world technologies

- Open questions for further research

- are these tentative findings representative of the industry as a whole?

- which set of methods have the largest influence on success?

- what makes new-to-the-world projects so much more successful than other projects?

-are the techniques employed fully and rigorously?

\section{Acknowledgements}

The authors would like to acknowledge Dr. Michael Craven at the University of Nottingham who designed the in-depth interview instrument, and all of our MATCH colleagues who also conducted interviews.

The authors would like to thank the referees for their very helpful comments and suggestions while reviewing this paper

This work has been funded by the MATCH Programme (EPSRC Grant GR/S29874/01). The views expressed, however, are entirely those of the authors. 


\section{Appendix}

The questionnaire was presented in three parts. Part I asked questions about the organisation itself, while parts II and III asked about a successful and less successful product. The questions that appeared in part III were identical to that in part II, therefore only parts I and II are shown here. The questionnaire also contained a brief description of the purpose of the questionnaire, an introduction to the project, the university logos, and a prepaid postal address. These also have not been included here due to space.

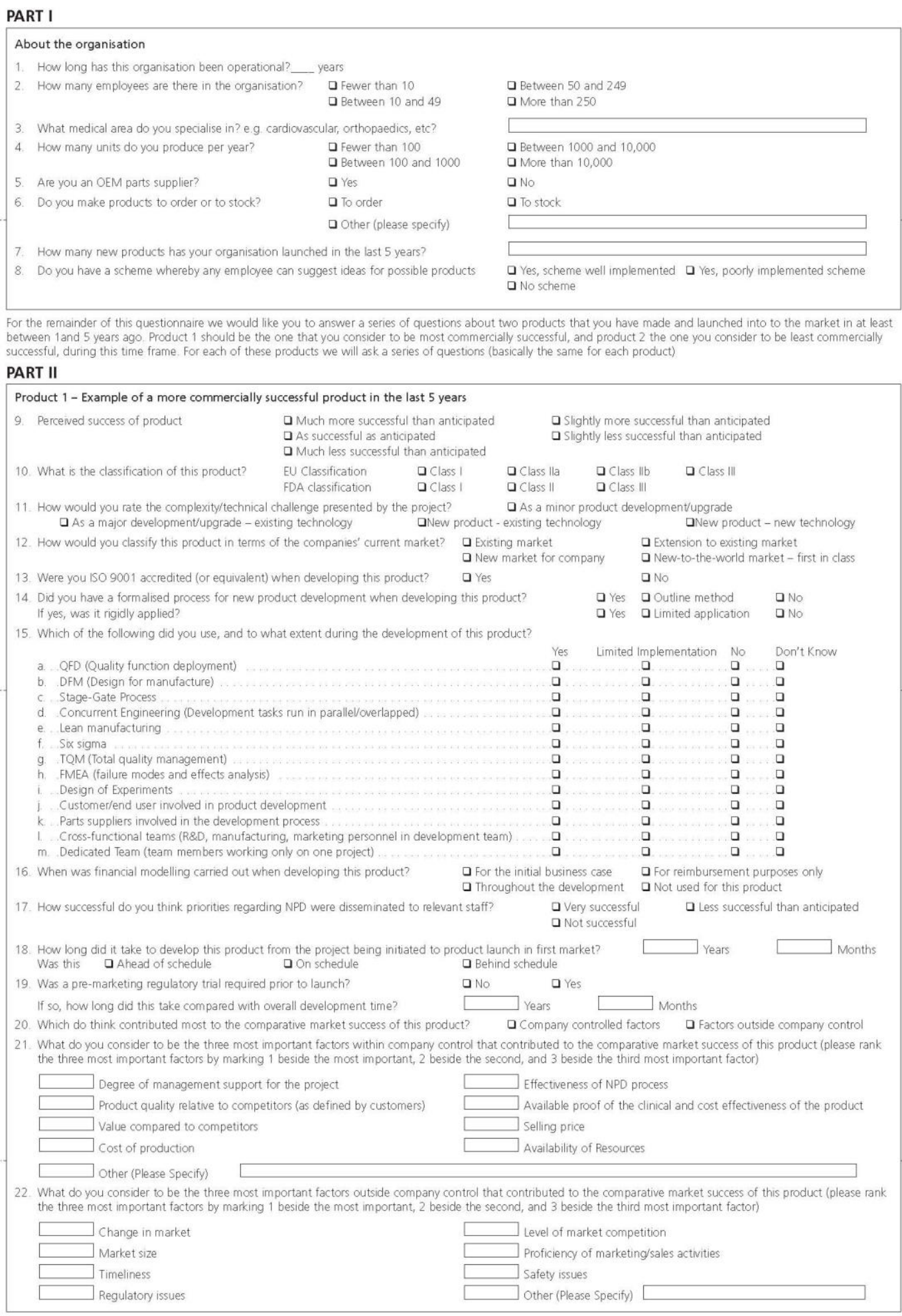




\section{References}

Achanga, P., E. Shehab, et al. (2006). "Critical success factors for lean implementation within SMEs." Journal of Manufacturing Technology Management 17(4): 460 - 471.

AdvaMed (2000). http://www.advamed.org/international/archive.shtml Accessed 6th December 2006

Araujo, C. S. and H. Benedetto-Neto (1996). "The utilization of product development methods: A survey of UK industry." Journal of Engineering Design 7(3): 265-277.

Birou, L. M. and S. E. Fawcett (1994). "Supplier Involvement in Integrated Product Development: A Comparison of US and European Practices." International Journal of Physical Distribution and Logistics Management 24(5): 4-14.

Booker, J. D. (2003). "Industrial Practice in designing for quality." International Journal of Quality and Reliability Management 20(3): 288-303.

Cha, K.-H. and Y. Xin (2006). "The Application of New Product Development Tools in Industry: The Case of Singapore." IEEE Transactions on Engineering Management 53(4): 543-554.

Cooper, R. G., S. J. Edgett, et al. (2002a). "Optimizing the Stage-Gate Process: What Best Practice Companies are Doing - Part 1." Research Technology Management 45(5): 21-27.

Cooper, R. G., S. J. Edgett, et al. (2002b). "Optimizing the Stage-Gate Process: What Best Practice Companies are Doing - Part 2." Research Technology Management 45(6): 43-49.

Copley, F. B. (1923). "Frederick W. Taylor: Father of Scientific Management" Harper \& Row, New York.

Crow, K. (2002). "Failure modes and effects analysis (FMEA)", DRM Associates. http://www.npd-solutions.com/fmea.html Accessed 11th December 2006

Deming, W. E. (2000). "Out of the Crisis" The MIT Press, Cambridge, Mass.

Dixon, D., A. Brown, et al. (2006a). "Experiences of New Product Development in the Medical Device Industry." Medical Device Technology 17(3), April: 20-22

Dixon, D., J. Eatock, et al. (2006b). "Application of Design of Experiment (DOE) Techniques to Process Validation in Medical Device Manufacture." Journal of Validation Technology 12(2): 92-100.

Driscoll, M. (2002). "Design for manufacture." Journal of Materials Processing Technology 122(2-3): 318-321.

Dunkerton, S. (2007). "KTNs: providing the infrastructure for innovation." Med Tech Business Review 2(1), Autumn/Winter: 70-73

Erlandson, B.-E. (2007). "Medtech products - from ideas to the market." Med Tech Business Review 1(4), Spring/Summer: 37-43

European Commission (1993). "Council Directive 93/42/EEC of 14 June 1993 concerning medical devices." Official Journal of the European Union L169: 1-43.

European Commission (2003). "Commission recommendation of 6 May 2003 concerning the definition of micro, small and medium-sized enterprises (2003/361/EC)." Official Journal of the European Union L124: 36-41.

Goldratt, E. (1994). "It's not luck" (1st ed), Gower, Aldershot.

Goldratt, E. and J. Cox (1993). "The Goal" (2nd ed), Gower, Aldershot.

Gould, J. D. and C. Lewis (1985). "Designing for usability: key principles and what designers think." Communications of the ACM 28(3): 300-311.

Harrison, A. (1995). "Business processes: their nature and properties." Examining Business Process Re-engineering. J. Peppard. London, Kogan Page. 
Harry, M. J. and R. Schroeder (1999). "Six Sigma, The Breakthrough Management Strategy Revolutionizing The World's Top Corporations" Currency, New York.

Healthcare Industries Task Force (HITF), Healthcare Industries Task Force (HITF) (2004). "Better healthcare through partnership: A programme for action" http://www.abhi.org.uk/multimedia/downloads/2004/hitf/coi-hitf-report.pdf

Hill, S. and A. Wilkinson (1995). "In search of TQM." Employee Relations 17(3): 8-25.

Institute of Quality Assurance "What is total quality management?" http://www.iqa.org/information/d2-4.shtml Accessed 11th December 2006

iSixSigma "Six Sigma - What is Six Sigma?" http://www.isixsigma.com/sixsigma/six sigma.asp Accessed 11th December 2006

Juran, J. (1979). "Quality Control Handbook" (3rd ed), McGraw Hill, New York.

Kandemir, D., R. Calantone, et al. (2006). "An exploration of organizational factors in new product development success." Journal of Business \& Industrial Marketing 21(5): 300-310.

Konda, R., K. P. Rajurkar, et al. (1999). "Design of experiments to study and optimize process performance." International Journal of Quality and Reliability Management 16(1).

Latino, R. J. (2004). "Optimizing FMEA and RCA efforts in health care." ASHRM journal 24(3): 21-28.

Laugen, B. T., N. Acur, et al. (2005). "Best manufacturing practices: What do the bestperforming companies do?" International Journal of Operations \& Production Management 25(2): 131-150.

National Institute for Clinical Excellence,(2004). "Guide to the Methods of Technology Appraisal"

OECD (2006). "OECD Health Data 2006", OECD. http://www.oecd.org/topicstatsportal/0,2647, en 28254956421111111 1,00.html Accessed 14th May 2007

Ohno, T. (1988). "Toyota Production System: Beyond Large-Scale Production" Productivity Press, Portland, Oregon.

QFD Institute "What is QFD?" http://www.qfdi.org/what is afd/what is gfd.htm Accessed 8th December 2006

Shewart, W. A. (1986). "Statistical method from the viewpoint of quality control" Dover Publications, London.

Smith, P. G. and D. G. Reinertsen (1998). "Developing products in half the time: new rules, new tools" (2nd ed), John Wiley and Sons.

Swink, M., S. Talluri, et al. (2006). "Faster, better, cheaper: A study of NPD project efficiency and performance tradeoffs." Journal of Operations Management 24(5): 542-562.

Thomas, A. and R. Barton (2006). "Developing an SME based six sigma strategy." Journal of Manufacturing Technology Management 17(4): 417 - 434.

Wen, Y. (1998). "Concurrent Engineering", Synthesis Coalition. http://best.me.berkeley.edu/ pps/pps/strategy.html Accessed 11the December 2006

Womack, J. P. and D. T. Jones (2003). "Lean Thinking" (Revised and Updated ed), Simon \& Schuster, London.

Zayas-Castro, J., R. Barton, et al. "Concurrent Engineering Course Materials", MEEP. http://www.mne.psu.edu/lamancusa/html/ConcEng.htm Accessed 11th December 2006

Zirger, B. J. and J. L. Hartley (1996). "The effect of acceleration techniques on product development time." IEEE Transactions on Engineering Management 43(2): 143-152. 